\title{
Azithromycin decolonization of STEC—a new risk emerges
}

\section{Michael E. Seifert and Phillip I. Tarr}

In our recent article (Azithromycin and decolonization after HUS. Nat. Rev. Nephrol. 8, 317-318; 2012), ${ }^{1}$ we raised questions about the value of decolonization following Shiga toxin-producing Escherichia coli (STEC) infections. ${ }^{2}$ We offered no specific objections to using azithromycin if decolonization was appropriate late in illness (that is, during or after hemolytic uremic syndrome [HUS]), but we did note that azithromycin might carry some risk of causing HUS if administered early in illness. ${ }^{3}$ However, newly published data that associate short-course azithromycin with sudden cardiac death ${ }^{4}$ prompt us to offer additional comment on the work by Nitschke and colleagues. Sudden deaths, quite plausibly caused by arrhythmias, represent approximately $10 \%$ of fatalities in patients with typical HUS, ${ }^{5-7}$ and myocardial ischemia can complicate HUS, even in children. ${ }^{8,9}$ Therefore, the risk of arrhythmias should not be minimized in patients with, or recovering from, HUS. These new data now compel us to restate our opinion that azithromycin has no role during or after STEC infections if used solely for the purpose of decolonization.

Department of Pediatrics, Division of Pediatric Nephrology, Southern Illinois University, 301 North $8^{\text {th }}$ Street, Pavilion 3A130, Springfield, IL 62701, USA (M. E. Seifert). Division of Pediatric Gastroenterology and Nutrition, Washington University School of Medicine, Campus Box 8208, 660 South Euclid Avenue, St Louis, MO 63110, USA (P. I. Tarr). Correspondence to: P. I. Tarr tarr@wustl.edu

\section{doi:10.1038/nrneph.2012.87-c1}

Competing interests

The authors declare no competing interests.

1. Seifert, M. E. \& Tarr, P. I. Azithromycin and decolonization after HUS. Nat. Rev. Nephrol. 8, 317-318 (2012).

2. Nitschke, M. et al. Association between azithromycin therapy and duration of bacterial shedding among patients with Shiga toxin- producing enteroaggregative Escherichia coli 0104:H4. JAMA 307, 1046-1052 (2012).

3. Wong, C. S. et al. Risk factors for the hemolytic uremic syndrome in children infected with Escherichia coli 0157:H7: a multivariable analysis. Clin. Infect. Dis. http://dx.doi.org/ 10.1093/cid/cis299.

4. Ray, W. A., Murray, K. T., Hall, K., Arbogast, P. G. \& Stein, C. M. Azithromycin and the risk of cardiovascular death, N. Engl. J. Med. 366, 1881-1890 (2012).

5. Robson, W. L., Leung, A. K. \& Montgomery, M. D. Causes of death in hemolytic uremic syndrome. Child Nephrol. Urol. 11, 228-233 (1991).

6. Abu-Arafeh, I., Gray, E., Youngson, G., Auchterlonie, I. \& Russell, G. Myocarditis and haemolytic uraemic syndrome. Arch. Dis. Child. 72, 46-47 (1995).

7. Taylor, C. M., White, R. H., Winterborn, M. H. \& Rowe, B. Haemolytic-uraemic syndrome: clinical experience of an outbreak in the West Midlands. Br. Med. J. (Clin. Res. Ed.) 292, 1513-1516 (1986).

8. Thayu, M. et al. Cardiac ischemia during hemolytic uremic syndrome. Pediatr. Nephrol. 18, 286-289 (2003).

9. Askiti, V., Hendrickson, K., Fish, A. J., Braunlin, E. \& Sinaiko, A. R. Troponin I levels in a hemolytic uremic syndrome patient with severe cardiac failure. Pediatr. Nephrol. 19, 345-348 (2004). 